\title{
Analysis of Fly Ash Concrete With Scanning Electron Microscopy and X-Ray Diffraction
}

\author{
Burhan Uzbaş ${ }^{1 *}$, Abdulkadir Cüneyt Aydın \\ 1 Department of Civil Engineering, Faculty of Engineering, Atatürk University, Erzurum, 25240, Turkey \\ * Corresponding author's e-mail: burhanuzbas@gmail.com
}

\begin{abstract}
In this study, the effects of using different ratios of fly ash on hydration products as well as the mechanical and microstructural properties of hardened concrete were investigated. Portland cement was replaced with 5\%,10\%, $15 \%$ and $20 \%$ fly ash (FA) by weight. The microstructural properties of the obtained samples were investigated by means of X-ray diffraction (XRD) and Scanning electron microscopy (SEM). Fly ash has negative effect on 7 days concrete strength; however, it was seen that fly ash increases the compressive strength of 28 and 90 days concrete. The XRD analysis showed that the ratio of calcium hydroxide $(\mathrm{CH})$, which is produced by hydration, decreases depending on the concrete age and the amount of fly ash. The SEM analysis showed that the usage of fly ash decreases gaps and increases C-S-H which is also a hydration production. When Portland cement was replaced with $10 \%$ fly ash by weight, compressive strength has increased and microstructure of concrete has improved. The reason for this is filling of gaps by fly ash and the decrease in the amount of $\mathrm{Ca}(\mathrm{OH})_{2}$ due to the reaction between fly ash and $\mathrm{Ca}(\mathrm{OH})_{2}$. Within this scope, the development in microstructure of fly ash concrete was evaluated in 90 days duration and a change of the development with compressive strength was investigated.
\end{abstract}

Keywords: fly ash; microstructure of concrete; scanning electron microscopy; x-ray diffraction; calcium hydroxide

\section{INTRODUCTION}

Thermal power plants which are used for energy generation release fly ash which is not only harmful for the environment but also not economical due to disposal [1]. Due to its dustiness, the fly ash resulting from the coal-based energy production is problematic to transport and store [2]. Cement, which is an important part of concrete, plays an important role in the cost of buildings. As a result of limited resources, the use of natural resources containing pozzolanic materials instead of cement is becoming increasingly important [3]. Using natural binders instead of cement has always been investigated because of the environmental and economical issues. Accordingly, using cost efficient and easily accessible materials for concrete production has become a widely studied field [4]. The fly ash consumption has been constantly increasing depending on demand for environmentally friendly binders and experience on using fly ash in field [5].
Instead of cement, the use of materials such as fly ash, silica fume, granulated blast furnace slag and metakaolin has been seriously considered by the cement industry to decrease the cement consumption [6]. In addition to cement, fly ash is intended to use in concrete production to decrease the $\mathrm{CO}_{2}$ emission, to decrease adequate energy which is consumed for cement production, to decrease the amount of waste products and to protect natural raw materials [7].

Concrete is considered as a cement-based composite which contains aggregates held together by hydrated cement paste [8]. Composite concrete gains strength with cement hydration. Hydration, i.e. a chemical reaction between water and cement constituents, constitutes an important time-dependent property of cement [9]. Although concrete is commonly used, its heterogeneous structure can cause unintended and negative effects [10]. One of the main parameters for concrete to gain strength is having developable mechanical properties. The 
mechanical property of cement-based material is needed by designers for stiffness and deflections evaluation and is fundamental for the proper modelling of its constitutive behaviour and its proper use in various structural applications [11]. Therefore, determining the mechanical properties of concrete is important for design [12]. In addition to this, because of the economical concerns, there is a strong demand for the use of natural sources. Application of natural sources in concrete production brings environmental, economical and/or technological advantages [13].

Fly ashes contain substantial amounts of $\mathrm{SiO}_{2}$, $\mathrm{Al}_{2} \mathrm{O}_{3}, \mathrm{Fe}_{2} \mathrm{O}_{3}$. Additionally, they can comprise $\mathrm{CaO}, \mathrm{MgO}, \mathrm{C}$ and $\mathrm{Na}_{2} \mathrm{O}$. The grain sizes of fly ashes differ between 1-150 $\mu \mathrm{m}$. Normally, their density are $2.1-2.7 \mathrm{gr} / \mathrm{cm}^{3}$ and their colors are light grey to dark grey [14]. Fly ash is the most common waste product which is formed by burning coal. The compound of pozzolan mainly contains $\mathrm{SiO}_{2}, \mathrm{Al}_{2} \mathrm{O}_{3}, \mathrm{Fe}_{2} \mathrm{O}_{3}$. These oxides are generally in amorphous form, which causes pozzolanic activity. Aluminosilicate glass which is formed from the products in the gas form which are obtained by burning coal and gathered by electrostatic separators contains small particles formed by mullite and quartz. When fly ash reacts with $\mathrm{Al}$ and $\mathrm{Si}$ oxides that have vitreous structure and is part of $\mathrm{Ca}(\mathrm{OH})_{2}$, calcium aluminate hydrate $(\mathrm{CAH})$ and calcium silicate hydrate (CSH) are formed [15].

$$
\begin{gathered}
\mathrm{Ca}(\mathrm{OH})_{2}+\mathrm{SiO}_{2}+\mathrm{nH}_{2} \mathrm{O}= \\
=\mathrm{CaOSiO}_{2}(\mathrm{n}+1) \mathrm{H}_{2} \mathrm{O}=(\mathrm{CSH}) \\
\mathrm{Ca}(\mathrm{OH})_{2}+\mathrm{Al}_{2} \mathrm{O}_{3}+{ }_{\mathrm{nH} 2 \mathrm{O}}= \\
=\mathrm{CaOAl}_{2} \mathrm{O}_{3}(\mathrm{n}+1) \mathrm{H}_{2} \mathrm{O}=(\mathrm{CAH})
\end{gathered}
$$

There are many studies on adding fly ash to concrete and it is commonly accepted that this affects viscosity, decreases hydration temperature and restrains alkali-silicate reactions. The influence of fly ash on the rate of hydration and properties of hardened cement composites depends on the chemical synthesis of fly ash, specific surface and chemical reaction (content of amorphous phase).

When fly ash is mixed with Portland cement and water, it forms products like ordinary cement hydration but they are less permeable and have denser microstructure [16]. Fly ashes are classified as pozzolans that produce cement products at ambient temperature. Fly ash contains amorphous and crystal elements such as quartz, mullite, magnetite and hematite [17]. The fly ash particles have spherical structure, high surface area and low loss of ignition. Moreover, it is known that the most soluble phase of fly ash is amorphous silicate [18].

Some of the pozzolanic materials can strengthen interfaces. Fly ash is a pozzolanic material that is used to produce high performance concrete and high volume fly ash concrete. Saito and Kawamura showed that fly ash significantly decreases the degree of orientation of calcium hydroxide $(\mathrm{CH})$ crystals and restrains precipitation of $\mathrm{CH}$ crystals and ettrengite formation at interface [19].

The study conducted by Rong showed that lots of fly ash particles fill pores by sinking into paste. The concrete obtained by using fly ash is relatively denser and more homogeneous than the concrete with no fly ash. Therefore, fly ash improves the mechanical properties of concrete due to decreasing the amount of $\mathrm{CH}$ and filling pores [20].

By using fly ash effectively, adequate, or even better technical performance can be obtained. Generally, fly ash concrete has high workability and low hydration temperature. Its early concrete strength is lower than concrete without fly ash; however, it has similar or higher concrete strength at later ages. This type of concrete is more resistant to deterioration by environmental factors [21]. Fly ash is used as supplemental material to provide a technical advantage by increasing the strength, decreasing the permeability and the hydration temperature. Adding fly ash to concrete mix increases the resistance to sulfate attack [22]. The study conducted by Kurt and others shows that increasing the fly ash amount in a concrete mix improves the property of self- consolidating concrete. This decreases the shear stress of concrete without increasing viscosity too much. Therefore, the loss of workability generally decreases with increasing ash and water content [23].

Fly ash concrete is generally used when special performance with respect to workability, strength and durability is required and it is not obtained by the accepted techniques and materials. The concrete samples having $10 \%$ and $20 \%$ fly ash were investigated by scanning electron microscopy (SEM) and it showed that concrete strength represents increasing dense microstructure [24]. Adding fly ash to concrete creates micro filler between gaps and pozzolanic reaction. The reason for pozzolanic reaction is that $\mathrm{SiO}_{2}$ and $\mathrm{Al}_{2} \mathrm{O}_{3}$ that are part of $\mathrm{Ca}(\mathrm{OH})_{2}$, react with fly ash. In addition to this, the pozzolanic reaction of fly ash is not significant in early hydration stage and it only behaves like a gap filler [25]. 
Adding some amounts of fly ash instead of cement is beneficial, because it increases the later age strength of concrete. In this study, the consequences of cement hydration process of fly ash concrete depending on time and mixture were evaluated. Specifically, the mechanical and physical properties of concrete produced by using fly ash were investigated by X-ray diffraction (XRD) and scanning electron microscopy (SEM) and comparison between results was made.

\section{MATERIALS AND METHODS}

In this study, Portland cement (CEM I 42.5) produced in Votorantim Hasanoğlan factory was used. Fly ash that was used in experiment was produced in Ares Cement factory in Seyitömer site. The amount of $\mathrm{SiO}_{2}, \mathrm{Al}_{2} \mathrm{O}_{3}, \mathrm{Fe}_{2} \mathrm{O}_{3}$ correspond to $87.7 \%$ of fly ash chemical composition and satisfies the conditions in TS-639. The chemical analysis and physical properties of fly ash are given in Table 1.

Size distribution of aggregates affects all of the properties of concrete. Therefore, in the study, standardized size distribution was used. Size distribution of aggregates that are used in concrete production was chosen depending on the largest grain size placement according to ideal area that was determined in TS-802 'Design Concrete Mixes'. In the study, sieve opening was 2,4,8 and $16 \mathrm{~mm}$. Max grain size was $16 \mathrm{~mm}$. Grain sizes were classified as $0-2$ and 2-4 for fine aggregate, $4-8$ and $8-16$ for coarse aggregate. $60 \%$ of coarse aggregate was chosen as $8-16 \mathrm{~mm}, 40 \%$ of coarse aggregate was chosen as $4-8 \mathrm{~mm}$. 34\% of fine aggregate was chosen as $2-4 \mathrm{~mm}, 66 \%$ of fine aggregate was chosen as $0-2 \mathrm{~mm}$. The comparison of the aggregate used in the study with

Table 1. Chemical composition of cement and fly ash used in the study

\begin{tabular}{|c|c|c|}
\hline \multicolumn{3}{|c|}{ Chemical composition } \\
\hline Oxides & Cement (\%) & Fly Ash (\%) \\
\hline $\mathrm{SiO}_{2}$ & 19.43 & 56.80 \\
\hline $\mathrm{Al}_{2} \mathrm{O}_{3}$ & 5.31 & 24.10 \\
\hline $\mathrm{Fe}_{2} \mathrm{O}_{3}$ & 3.79 & 6.80 \\
\hline $\mathrm{CaO}$ & 64.39 & 1.40 \\
\hline $\mathrm{MgO}$ & 2.25 & 2.40 \\
\hline $\mathrm{K}_{2} \mathrm{O}$ & 0.90 & - \\
\hline $\mathrm{Na}_{2} \mathrm{O}$ & 0.09 & - \\
\hline $\mathrm{SO}_{3}$ & 2.47 & 2.90 \\
\hline Loss of ignition & 1.07 & 0.80 \\
\hline
\end{tabular}

the reference granulometry is given in Figure 1. The water/binder ratio was chosen as $60 \%$ in the concrete samples produced in the study and it was constant during the experiment.

The analytical XRD and SEM techniques were used to determine the crystal structure of concrete samples. Additionally, different mixing ratios were used to produce concrete with and without fly ash. Cement was replaced with fly ash which is $5 \%, 10 \%, 15 \%$ and $20 \%$ by weight. Five different concrete samples control specimen (CS), concrete containing 5\% fly ash (FA5), concrete containing $10 \%$ fly ash (FA10), concrete containing $15 \%$ fly ash (FA15) and concrete containing $20 \%$ fly ash (FA20) were prepared for the study. A rotary concrete mixer was used to mix the samples. The materials were mixed before adding water. Then, mixing was continued by adding water until mixture became homogeneous ( 3 minutes). The obtained mixtures were compacted by skewering after placing them in greased 150x150x150 mm steel cube molds. The samples were unmolded after waiting 24 hours and they were cured for 7, 28, 90 days by putting in curing pool which was $20{ }^{\circ} \mathrm{C}$. Three samples for each age, in total 9 samples were prepared. The mixing ratios for samples are given in Table 2 . The compressive strength test was performed for samples at 7, 28, 90 days of age. After crushing, the samples were taken from all of the mixtures for microstructure analysis by XRD and SEM.

The samples for SEM and XRD were prepared. The prepared samples were placed in a container filled with acetone and kept free of dust,
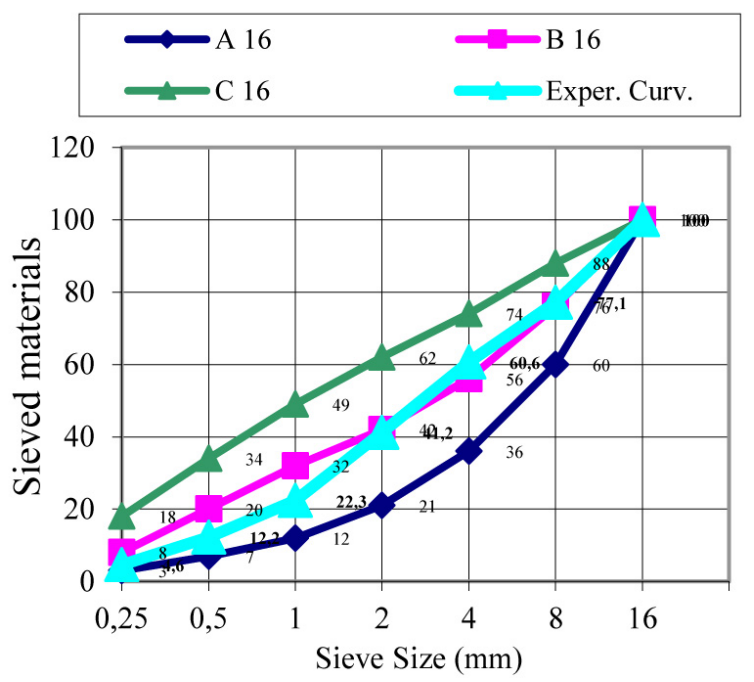

Figure 1. Size Distribution (TS 802 Standard Curves and Experiment Curve) 
Table 2. Mixing ratios of fly ash concrete

\begin{tabular}{|c|c|c|c|c|c|c|}
\hline \multicolumn{2}{|c|}{$\operatorname{Mixes}\left(1 \mathrm{~m}^{3}\right)$} & Control & $\% 5$ FA & $\% 10 \mathrm{FA}$ & $\% 15 \mathrm{FA}$ & $\% 20 \mathrm{FA}$ \\
\hline \multicolumn{2}{|c|}{ Water/Binder } & 0.60 & 0.60 & 0.60 & 0.60 & 0.60 \\
\hline \multicolumn{2}{|c|}{ Cement (kg) } & 350.00 & 332.5 & 315.00 & 297.50 & 280.00 \\
\hline \multicolumn{2}{|c|}{ Water (kg) } & 210.00 & 210.00 & 210.00 & 210.00 & 210.00 \\
\hline \multirow{4}{*}{ Aggregate $(\mathrm{kg})$} & $0-2 \mathrm{~mm}$ & 689.00 & 671.00 & 674.00 & 666.00 & 659.00 \\
\hline & 2-4 mm & 350.00 & 350.00 & 350.00 & 350.00 & 350.00 \\
\hline & $4-8 \mathrm{~mm}$ & 280.00 & 280.00 & 280.00 & 280.00 & 280.00 \\
\hline & $8-16 \mathrm{~mm}$ & 420.00 & 420.00 & 420.00 & 420.00 & 420.00 \\
\hline \multicolumn{2}{|c|}{ Fly ash $(\mathrm{FA})(\mathrm{kg})$} & 0.00 & 17.50 & 35.00 & 52.50 & 70.00 \\
\hline
\end{tabular}

dirt, etc. that did not belong to the sample. The cleaned specimens are stored in the desiccator and the contact with the surface is prevented. Since the concrete sample contains the insulated phase for the SEM examination, the surface is covered with a thin conductive layer. The coating interaction is coated with gold metal, which is small in volume. The samples were subjected to a SEM analysis.

\section{RESULTS AND DISCUSSIONS}

\section{Concrete strength}

The compressive strengths of 7, 28 and 90 days of concrete are given in Table 3. In Figure 2, the effects of fly ash on compressive strengths of 7,28, 90 days of concrete are showed. The use of fly ash as a binder instead of cement yields better results on compressive strength than control sample at later ages.

In Table 3, the compressive strengths of mixtures with fly ash were compared with the control sample. According to Figure 2, the compressive strengths of concrete samples with fly ash were lower than the control sample after 7 days curing. In this group; i.e., after 7 days curing, FA5 had the highest compressive strength and FA20 had the lowest. The amount of fly ash increased, while the compressive strength decreased. This

Table 3. Compressive strength at 7, 28, 90 days

\begin{tabular}{|c|c|c|c|}
\hline Mixes & $\begin{array}{c}\text { Compressive } \\
\text { Strength } \\
\text { MPa (7 days) }\end{array}$ & $\begin{array}{c}\text { Compressive } \\
\text { Strength MPa } \\
\text { (28 days) }\end{array}$ & $\begin{array}{c}\text { Compressive } \\
\text { Strength MPa } \\
\text { (90 days) }\end{array}$ \\
\hline CS & 32.49 & 38.34 & 40.28 \\
\hline FA5 & 31.28 & 39.62 & 40.59 \\
\hline FA10 & 30.48 & 40.69 & 41.95 \\
\hline FA15 & 29.28 & 40.05 & 41.56 \\
\hline FA20 & 29.07 & 38.91 & 40.33 \\
\hline
\end{tabular}

trend continued linearly when the fly ash amount was increasing at 7 days.

After 28 days curing, the compressive strengths of concrete mixes with different ratios of fly ash were generally higher than in the control sample. In this group, FA10 showed the highest compressive strength and CS showed the lowest. When the fly ash ratio was more than $10 \%$ by weight of cement, the compressive strength decreased and FA20 came close to CS.

After 90 days of curing, the development of pressure resistance was similar to that of 28 days of age. The compressive strengths of fly ash-containing concrete mixtures were generally higher than the control sample. In this group, the FA10 sample had a higher compressive strength than the other samples, while the CS had a lower compressive strength after 28 days of curing. As it was 28 days old, when the fly ash ratio was greater than $10 \%$, a decrease of compressive strength occurred and the FA20 sample showed close pressure resistance to CS.

When the results were evaluated, it was seen that at 7 days of age, the compressive strengths were decreasing at all ratios and at 28 days and 90 days. The compressive strength for all mixtures increased along with the amount of fly ash

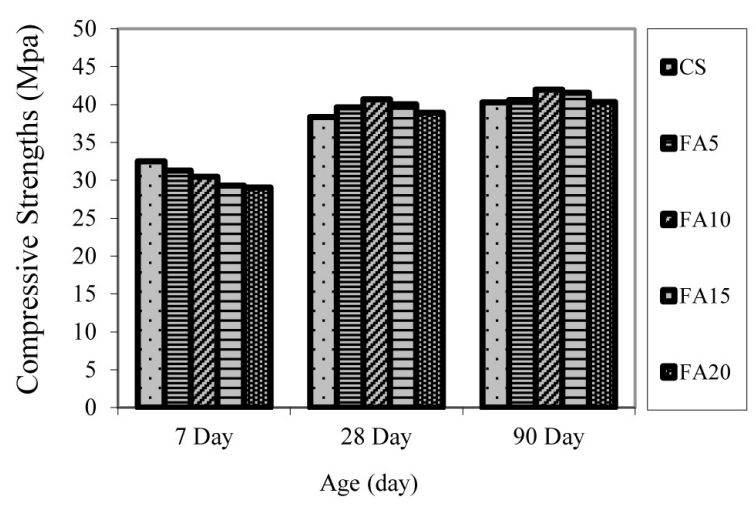

Figure 2. Comparison of 7, 28, 90 days of concrete mixes with control sample 
in concrete. The reason for this, is because the fly ash particle size is smaller than cement; thus, fly ash fills the gaps at the interface between aggregates and cement while the hydration products of oxides in fly ash increase the pozzolanic reaction with $\mathrm{Ca}(\mathrm{OH})_{2}$.

Memon observed that mineral and chemical additives had positive effects on the compressive strength of concrete, porosity and pore size distribution [26]. The data from the study also supports this result. In the study by Zheng et al., it was found that the addition of activated carbon into the fly ash cement mortar improves the pressure resistance and the strength increases along with the active carbon content. The mixtures containing $20 \%$ fly ash $+4 \%$ active carbon were found to have the highest compressive strength in 28 days [27].

\section{SEM and XRD}

SEM measures the signals coming from interaction between sample and electron beam by scanning electron beam passing through samples. The fracture surface analysis can be used to investigate surface view, particle size and shape and fracture surface and, polished surface can be used to determine the phase distribution and chemical composition. X-Ray micro analysis provides elemental mapping and quantitative point chemical analysis. Back scattered electron imaging and $\mathrm{X}$-Ray screening are the best practicable screening modes for quantitative scanning electron microscope. The computer-based image processing and analysis (IA) makes quantitative screening possible [28].

The SEM analysis is a high performance method to investigate the materials of structure. The SEM analysis is characterized with easy preparation of samples, variety of accessible knowledge, good resolution about high depth of field and ever expanding. The XRD method can be used to determine the crystal structure of samples, quantitative and qualitative phase analysis, to investigate phase transformation, to study crystallographic configuration and to study size of crystals [29]. In this study, the SEM and XRD analyses were conducted on same samples and the results were evaluated accordingly.

The mechanical properties of concrete develop when fly ash is used properly. Fly ash shows pozzolanic properties by reacting with $\mathrm{Ca}(\mathrm{OH})_{2}$ which is a Portland cement hydration product. This pozzolanic reaction forms calcium silicate hydrate (C-S-H) and calcium aluminate silicate hydrate (C-A-S-H). The control sample and five different mixture samples (CS, FA5, FA10, FA15 and FA20) were analyzed with SEM and XRD and the results were given (Fig. 3-17).

JSM5600 scanning electron microscope (SEM) with $30 \mathrm{kV}$ in Scientific and Technological Research Center in Kırıkkale University was used in SEM analysis of produced samples. Cu X-Ray Tube Panalytical X'Pert Powder in Mineralogy and Petrography Research Department of General Directorate of Mineral Research and Exploration was used for the XRD analyses.

Hydrated cement paste includes hydration products which are portlandite $(\mathrm{CH})$, calcium silicate hydrate (C-S-H), ettringite and clinker minerals that are not hydrated. Cement paste with fly ash forms different ratios of $\mathrm{CH}$ at all hydration ages in comparison with the cement which does not include any additives. Moreover, $\mathrm{CH}$ is formed in greater amounts in the cement paste with fly ash than in the case of Portland cement paste at all ages. This shows that hydration develops at different ratios (Fig. 18)

The X-Ray diffraction method shows that the amount of hydration products differs depending on cement hydration at 7,28 and 90 days of age.

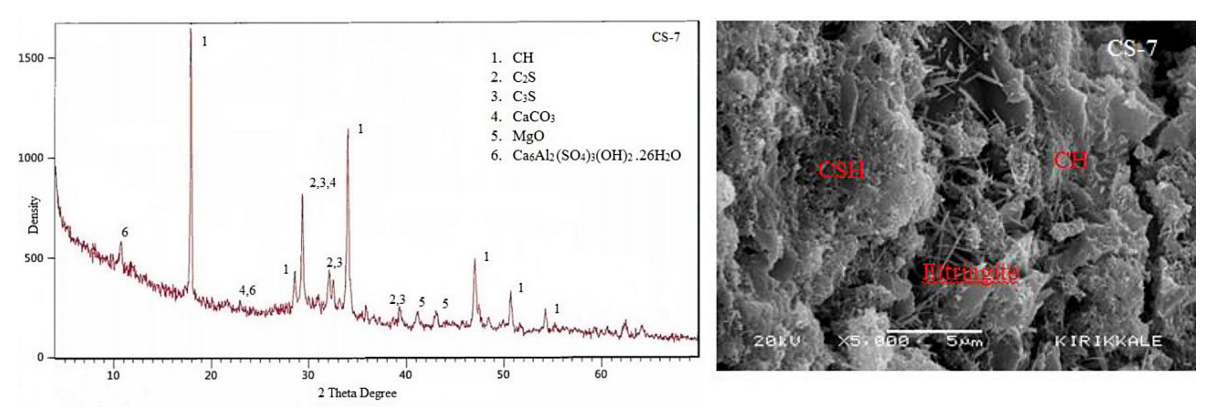

Figure 3. SEM and XRD analyses of the CS sample (7 days). CH (Portlandit), C-S-H gels and ettringite are seen in the analysis of the CS sample. When the CS sample is compared with other samples containing fly ash, it can be seen that the gaps between phases are much larger and $\mathrm{CH}$ and ettringite exist prominently at 7 days of age. 

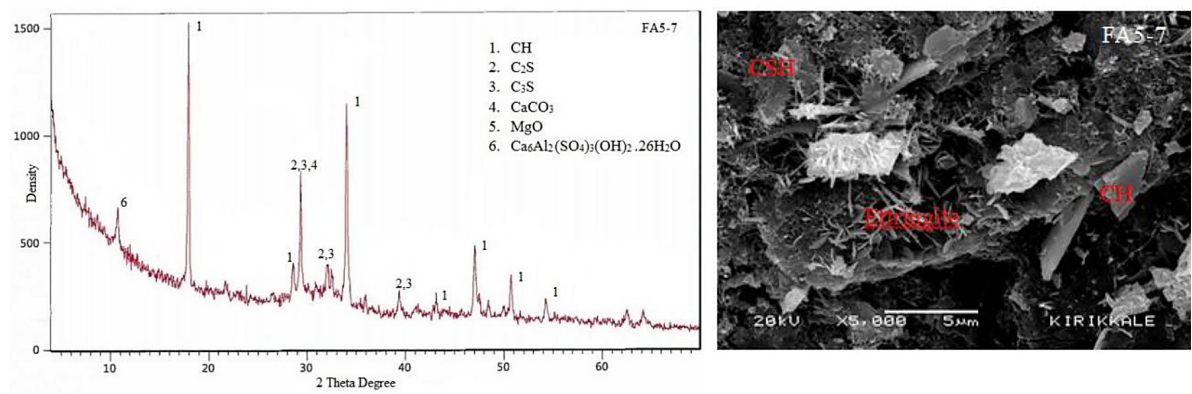

Figure 4. SEM and XRD analyses of the FA5 sample (7 days). CH, C-S-H gels and ettringite are seen in the analysis of the FA5 sample as in the CS sample. When the FA5 sample is compared with the CS sample, it can be seen that the gaps between phases are smaller and $\mathrm{CH}, \mathrm{C}-\mathrm{S}-\mathrm{H}$ and ettringite exist as in the $\mathrm{CS}$ sample at 7 days of age.
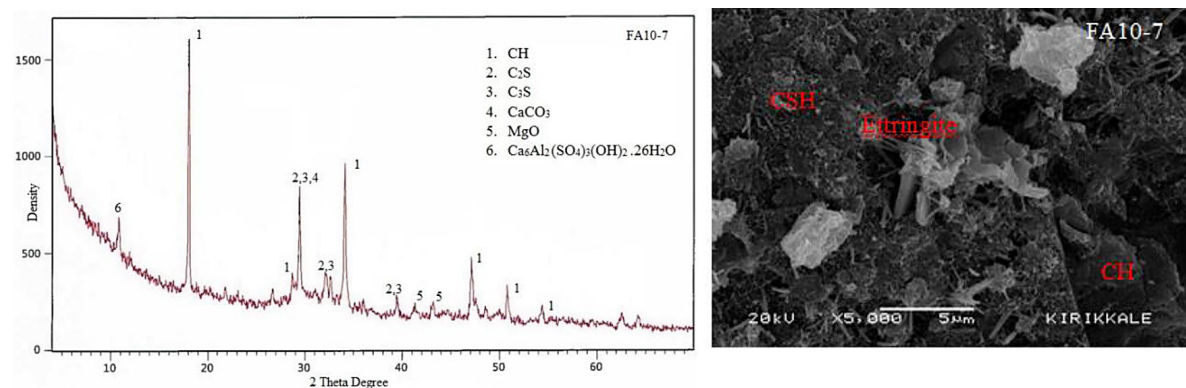

Figure 5. SEM and XRD analyses of the FA10 sample (7 days). CH, C-S-H gels and ettringite are seen in the analysis of the FA10 sample as in the CS sample. When the FA10 sample is compared with the CS sample, it can be seen that the gaps between phases are continuing to decrease and CH, C-S-H and ettringite exist as in the CS sample at 7 days of age. The amount of ettringite is less than in the FA5 and CS samples.
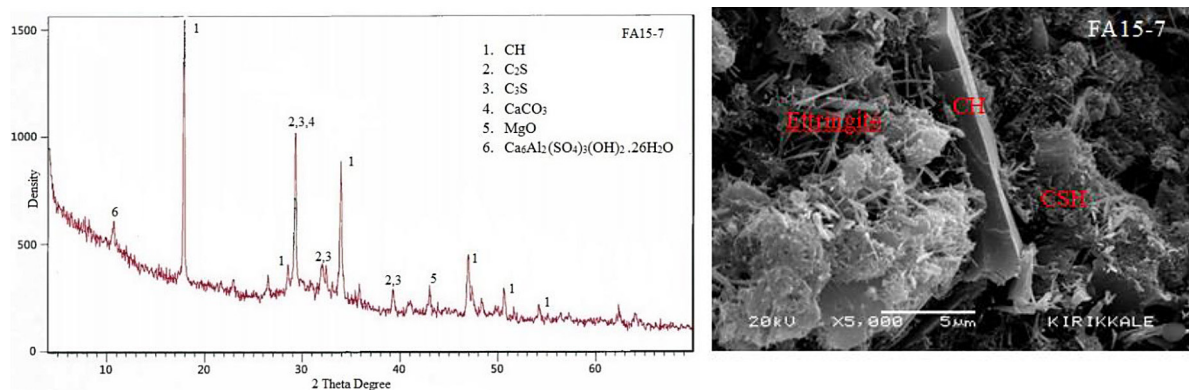

Figure 6. SEM and XRD analyses of the FA15 sample (7 days). CH, C-S-H gels and a small amount of ettringite are seen in the analysis of the FA15 sample as in the CS sample. When the FA15 sample is compared with the CS sample, it can be seen that the gaps between phases much larger than in the CS and FA5,FA10 samples and $\mathrm{CH}$ and C-S-H exist prominently as in the CS sample at 7 days of age. When this sample is compared with the

FA10 sample, more ettringite exists.

This method also shows the existence of mineral compounds that contribute to an increase and development of hydration products at 7,28 and 90 days of age.

It was observed that while $\mathrm{Ca}(\mathrm{OH})_{2}$ significantly decreases with time, while C-S-H increases. After 7,28 and 90 days of curing of the FA5, FA10 , FA15 and FA20 samples which include fly ash, as can be seen at peaks in XRD analysis $\mathrm{CH}$ peaks, decrease.
Adding fly ash instead of cement decreased the $\mathrm{CH}$ formation which is a hydration product. However, lower compressive strength was obtained when compared to the CS sample at 7 days of age. At later ages ( 28 and 90 days), by reaction of $\mathrm{CH}$ and oxides in fly ash, C-S-H gel which had a pozzolanic structure was produced so the strength values reached or exceeded the values of the CS sample (Fig. 18). 

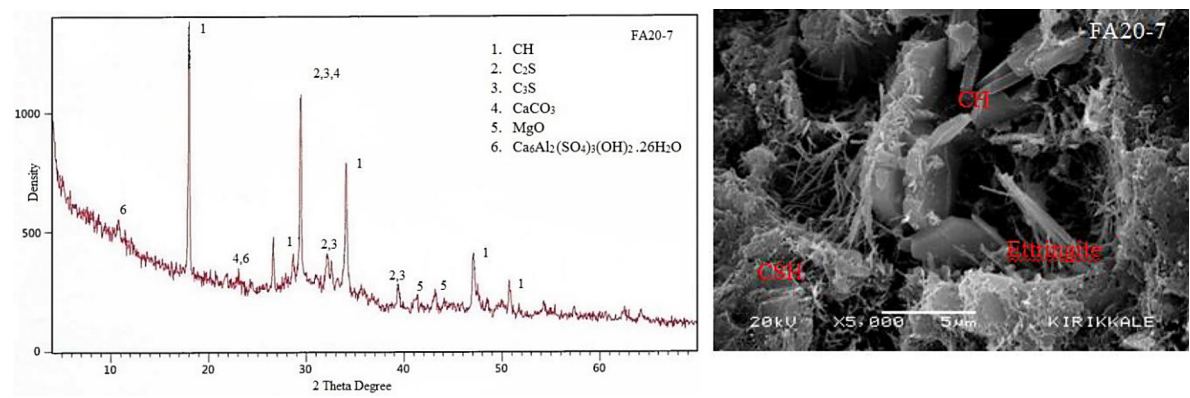

Figure 7. SEM and XRD analyses of the FA20 sample (7 days). CH, C-S-H gels and ettringite are seen in the analysis of the FA15 sample as in the CS and other samples. When the FA20 sample is compared with the CS sample, it can be seen that the gaps between phases are much larger than in CS and other samples and CH and ettringite exist prominently as in the CS sample at 7 days of age.
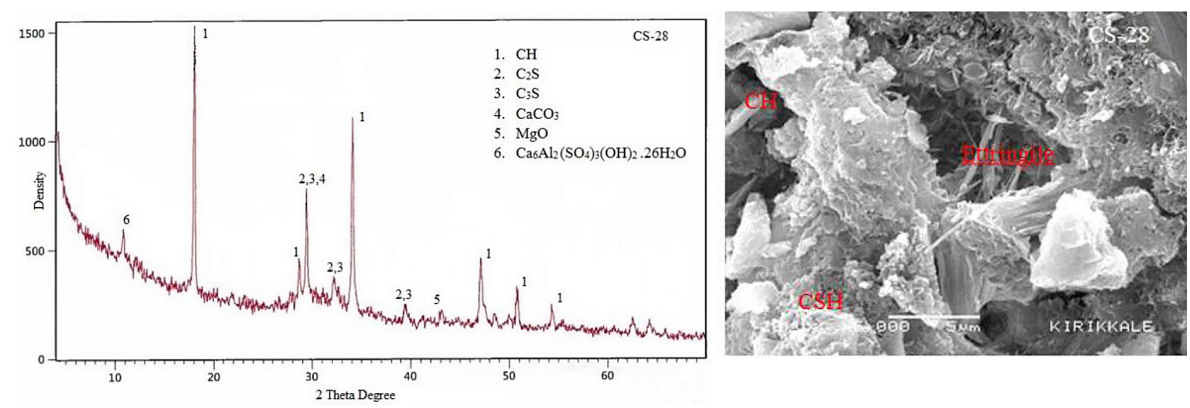

Figure 8. SEM and XRD analyses of the CS sample (28 days). CH (Portlandite), C-S-H gels and large amount of ettringite are seen in the analysis of the CS sample. When the CS sample is compared with other samples with fly ash, it can be seen that the gaps between phases are much larger and $\mathrm{CH}$ exists at 28 days of age.

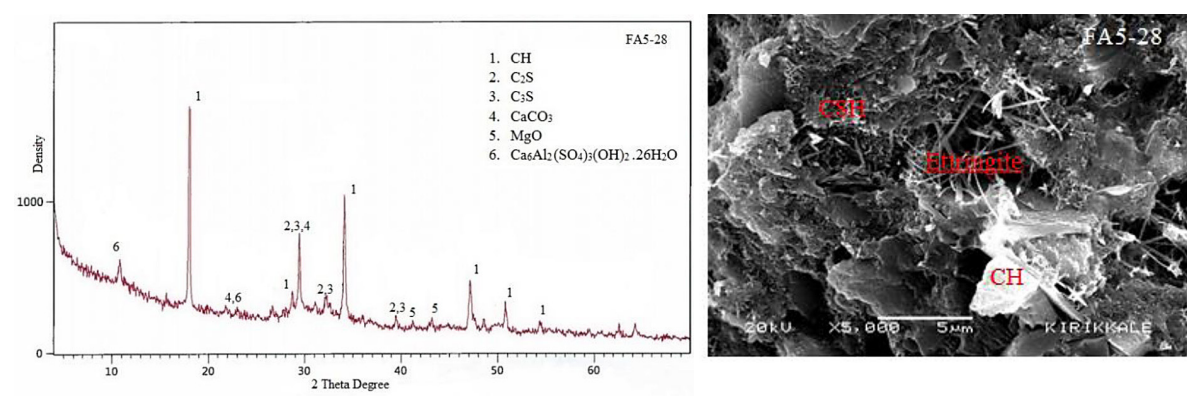

Figure 9. SEM and XRD analyses of the FA5 sample (28 days). CH (Portlandite), C-S-H gels and ettringite are seen in analysis of FA5 sample. When FA5 sample is compared with CS sample, it can be seen that gaps between phases are similar with $\mathrm{CS}$ sample and small amount of $\mathrm{CH}$ and ettringite exist at 28 days of age.

Ma and Brown investigated the hydration reactions of fly ash and observed calcium silicate hydrate, tricalcium aluminum hydrate and ettringite during the XRD analysis. It was seen that the change in reactivity depends on added $\mathrm{Ca}(\mathrm{OH})_{2}$ , $\mathrm{CaSO}_{4} .2 \mathrm{H}_{2} \mathrm{O}$. Goni studied the pozzolanic reaction of fly ash and the effects of produced compounds, and showed that alkalis play an important role on the reactivity under hydration conditions compared to the fly ash sensitivity [30].

In order to determine the chemical compounds of basic materials, the midproduct and the final product, it is important to obtain and use the required products. Therefore, investigation of the reactions during hydration of cement which is a part of concrete and gives bindingness property, by X-Ray Diffraction (XRD) and scanning electron microscope (SEM) has attracted researchers [31].

Dorum et al. observed that the portlandite, calcium silicate hydrate and ettringite, hydrated cement clay hydration products containing fly ash, as well as unhydrated clinker minerals, were in the same run. It was observed that the amount of fly ash-containing dough, $\mathrm{CH}$, formed 

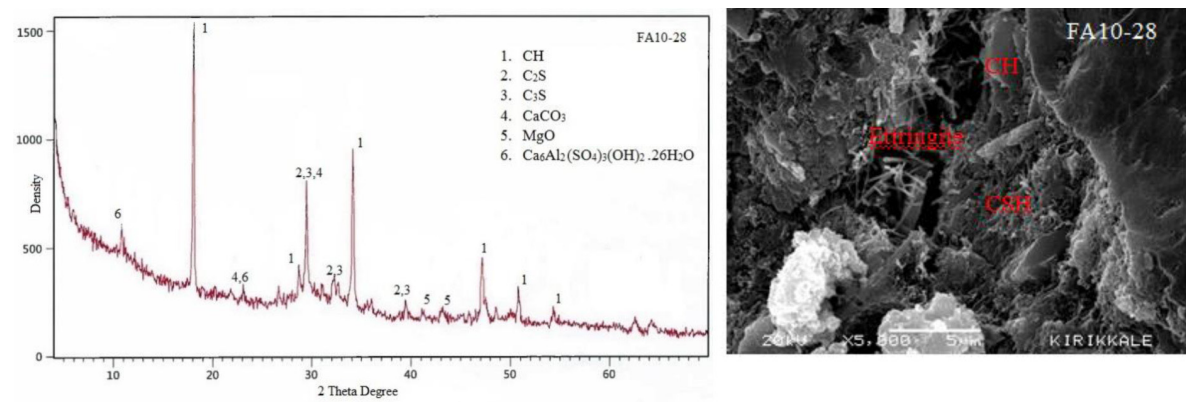

Figure 10. SEM and XRD analyzes of the FA10 sample (28 days). CH (Portlandite), C-S-H gels and ettringite are seen in the analysis of the FA10 sample. When the FA10 sample is compared with the CS sample, it can be seen that the gaps between phases are smaller and a small amount of $\mathrm{CH}$ and ettringite exist at 28 days of age.

Moreover, gaps decrease and denser structure is obtained.
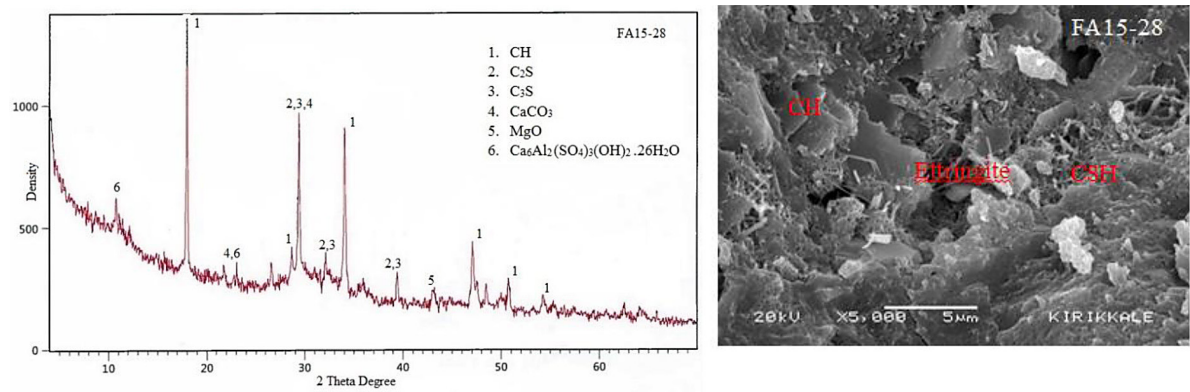

Figure 11. SEM and XRD analyses of FA15 sample (28 days). CH (Portlandite), C-S-H gels and a small amount of ettringite are seen in the analysis of the FA15 sample. When the FA15 sample is compared with the CS sample, it can be seen that the gaps between phases are lesser and a small amount of $\mathrm{CH}$ and ettringite exist at 28 days of age.
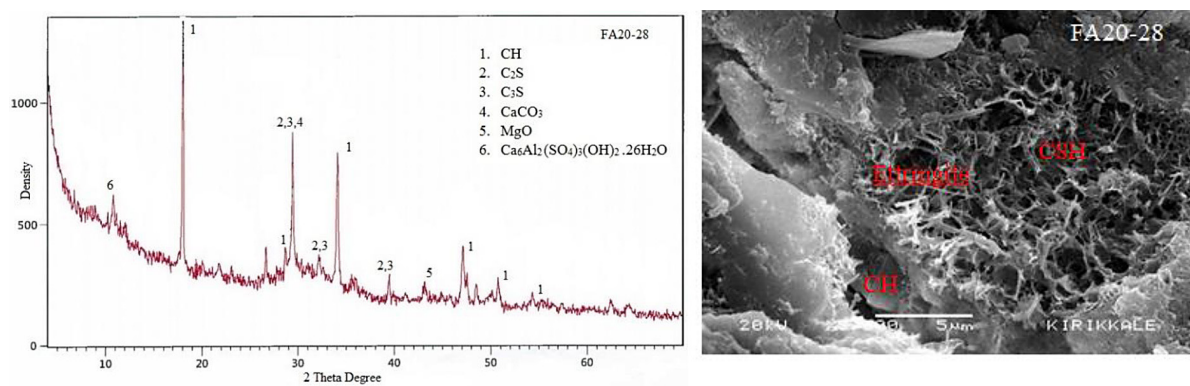

Figure 12. SEM and XRD analyses of the FA20 sample (28 days). CH (Portlandit), C-S-H gels and a small amount of ettringite are seen in the analysis of the FA20 sample. When the FA20 sample is compared with the $\mathrm{CS}$ sample, it can be seen that the gaps between phases are lesser and a small amount of $\mathrm{CH}$ and ettringite exist at 28 days of age.

at different rates on all days of hydration, and the fly ash content of all ages was lesser than that of the non-containing dough. This demonstrates that the hydration progression in the dough occurs at different rates [32]. The results obtained without the work done are in agreement with the conducted research.

In SEM studies, adding activated carbon in fly ash mixtures resulted in filling gaps with calcium silicate hydrate $(\mathrm{C}-\mathrm{S}-\mathrm{H})$ and ettringite which are hydration products. Therefore, adding activated carbon to fly ash affected the microstructure of concrete positively and mixtures with higher strength were obtained [23]. Similarly to this study, when the SEM images were examined, $\mathrm{C}-\mathrm{S}-\mathrm{H}, \mathrm{C}-\mathrm{H}$ and ettringite existed in the samples. While the $\mathrm{CH}$ density which depended on age and using of fly ash decreased, the amount of CSH increased. In the SEM analyses, the amount of ettringite generally decreased depending on age.

The correct use of fly ash improves the mechanical properties of concrete. Fly ash, Portland 

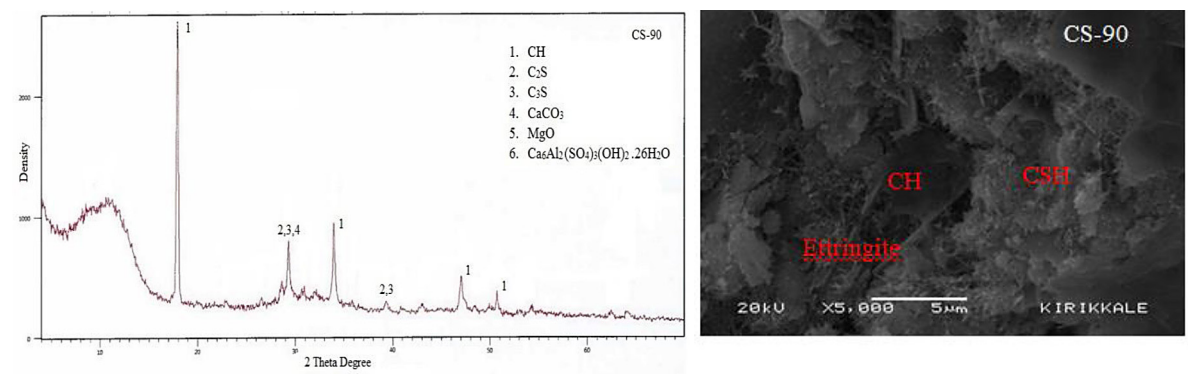

Figure 13. SEM and XRD analyzes of the CS sample (90 days). CH (Portlandite) and C-S-H gels are seen in the analysis of the CS sample. When the CS sample is compared with other samples with fly ash, it can be seen that the gaps between phases are much larger and $\mathrm{CH}$ exists at 90 days of age.
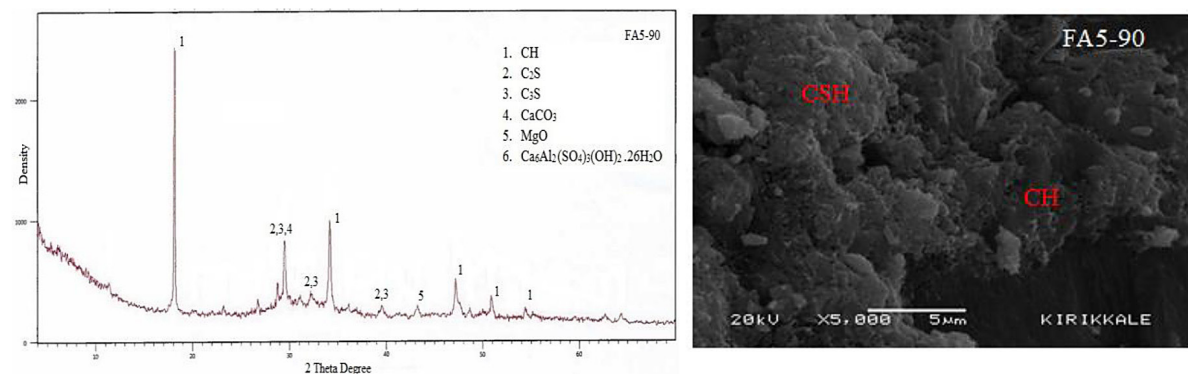

Figure 14. SEM and XRD analyses of the FA5 sample (90 days). $\mathrm{CH}$ and $\mathrm{C}-\mathrm{S}-\mathrm{H}$ gels are seen in the analysis of FA5 sample. When the FA5 sample is compared with the CS sample, it can be seen that the gaps between phases are lesser and a small amount of $\mathrm{CH}$ exists at 90 days of age.
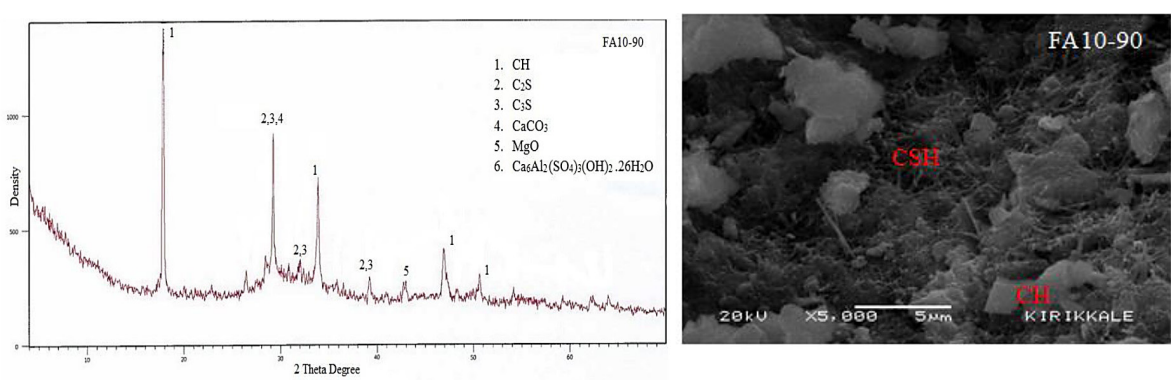

Figure 15. SEM and XRD analyses of the FA10 sample ( 90 days). CH, C-S-H gels and small amounts of ettringite are seen in the analysis of the FA10 sample. When the FA10 sample is compared with the CS sample, it can be seen that the gaps between phases are lesser and a small amount of $\mathrm{CH}$ exists at 90 days of age.

hydration products of cement with $\mathrm{Ca}(\mathrm{OH})_{2}$ show the pozzolanic properties, from the reaction calcium-silicate-hydrate (C-S-H) and calcium aluminate silicate hydrate products (C-A-S-H) [33].

\section{CONCLUSIONS}

Fly ash delivers great performance in concrete because a large amount of silica exists in it and it shows strong pozzolanic property that reaches high strength and increases the durability of concrete. Therefore, using fly ash in cement or concrete is still a subject that should be studied by researchers.
The percentage of portlandite in samples generally decreased when fly ash was used instead of cement. As can be seen in Figure 2, adding fly ash to concrete affected the 7-day strength negatively; however, the compressive strength increased in 28 and 90 days.

Throughout the ages, during the chemical reaction of Portland cement, silicates reacted with free $\mathrm{Ca}(\mathrm{OH})_{2}$ to form amorphous C-S-H gel. For this reason, the amount of $\mathrm{Ca}(\mathrm{OH})_{2}$, which is harmful for durability and concrete durability, is reduced due to the volatile matter used. The addition of fly ash decreased the $\mathrm{CH}$ concentration by $51.70 \%$ at 90 days of age. As a result, it was observed that cement hydration increased in later 

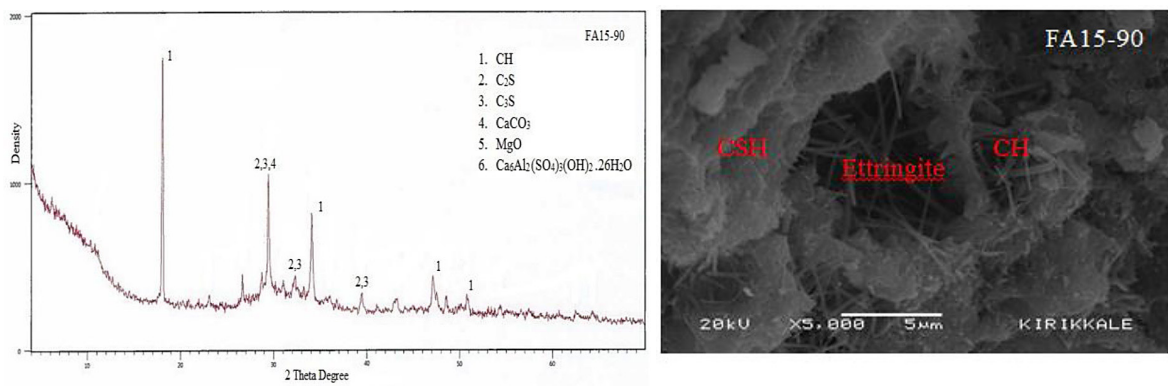

Figure 16. SEM and XRD analyses of the FA15 sample (90 days). CH, C-S-H gels and small amounts of ettringite are seen in the analysis of the FA15 sample. When the FA15 sample is compared with the CS sample, it can be seen that the gaps between phases are lesser and a small amount of $\mathrm{CH}$ exists at 90 days of age.
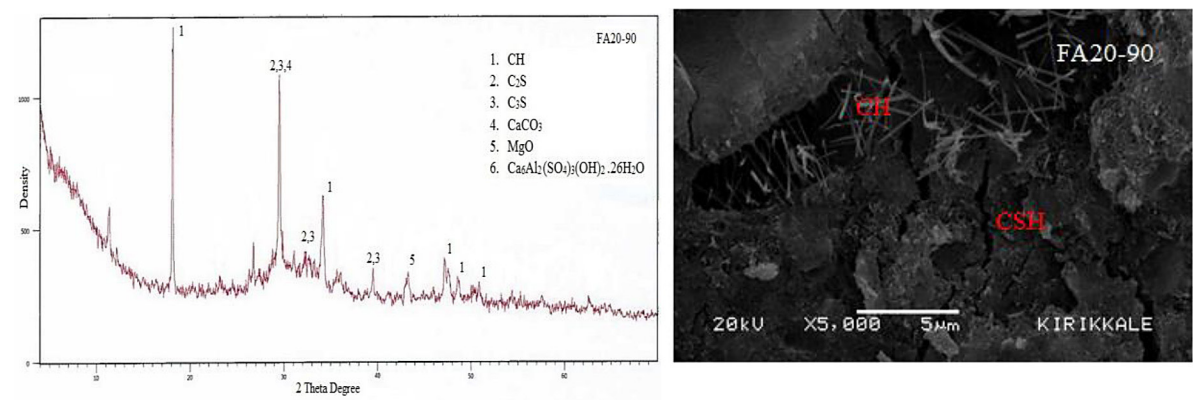

Figure 17. SEM and XRD analyses of the FA20 sample (90 days). CH, C-S-H gels and small amounts of ettringite are seen in the analysis of the FA20 sample. When the FA20 sample is compared with the CS sample, it can be seen that the gaps between phases are lesser and small amount of $\mathrm{CH}$ exists at 90 days of age.

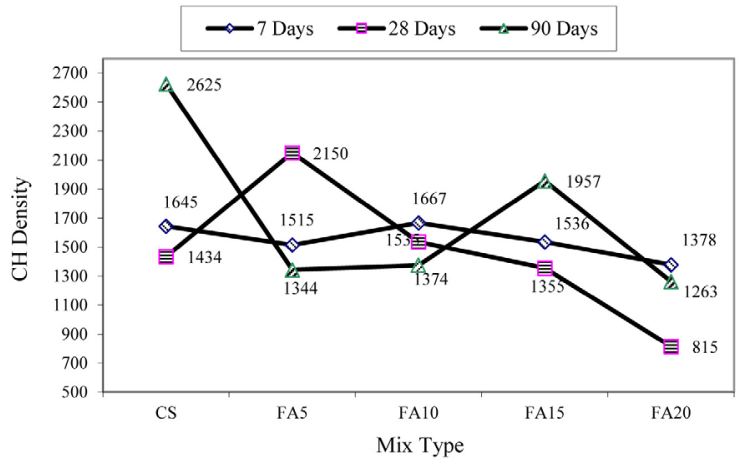

Figure 18. Effect of fly ash on density

ages due to the high surface area of fly ash cement that improved the C-S-H density. As the content of fly ash increased, the void ratio of the concrete decreased. It has been seen that the fly ash develops both the mechanical properties and durability of concrete during the ages.

The presence of portlandite peaks observed in both XRD and SEM analyses of the cured samples showed that these peaks decreased with fly ash after hydration at varying ages. The resulting portlandites showed that the resulting $\mathrm{C}_{3} \mathrm{~S}$ and $\mathrm{C}_{2} \mathrm{~S}$ combined with the fly ash resulted in C-S-H, and the resulting C-S-H density increased by $33.99 \%$. The chemical interaction with fly ash addition to concrete leads to the $\mathrm{Ca}(\mathrm{OH})_{2}$ consumption in the resulting cement hydration.

Therefore, using $10 \%$ fly ash instead of cement in the situations that do not require early age resistance will provide many advantages over unplasticized concrete. When the microstructure analysis and hydration of concrete were examined, it was concluded that the SEM and XRD analyses should be evaluated together. In addition, it is possible to determine the properties such as the amount of hydration products and hydration products, concrete age and strength values, which will be provided by SEM and XRD in concrete sections.

\section{REFERENCES}

1. Topçu İ.B. (2016). Uçucu kül kullanımının betondaki etkileri. ResearchGate.

2. Borowski G., Hycnar J.J. (2016). The effect of granulated fly ashes with phosphogypsum on the hardening of cement mortar. Technical Transactions - Civil Engineering, 113, 2-B (7), 37-45.

3. Aydın A.C, Gül R. (2007). Influence of volcanic originated natural materials as additives on the setting time and some mechanical properties of concrete. Construction and Building Materials, 21, 1277-1281. 
4. Oğuz E., Aydın A.C. (2003). Prediction of adsorption rate of phosphate removal from wastewater with gaz concrete. International Journal of Environment and Pollution 19 (16), 603-614.

5. Celik, K., Meral, C., Mancio, M., Mehta, P.K., Monteiro, P.J. (2014). A comparative study of self-consolidating concretes incorporating high-volume natural pozzolan or high-volume fly ash. Construction and Building materials, 67(9), 14-19.

6. Ranjbar N., Mehrali M., Behnia A., Alengaram U. J., Jumaat M.Z. (2014). Compressive strength and microstructural analysis of fly ash/palm oil fuel ash based geopolymer mortar. Materials and Design 59, 532-539.

7. Jozic D., Zelic J. (2006). The effect of fly ash on cement hydration in aqueous suspensions. Faculty of Chemical Technology, Seramics - Silikaty 50 (2), 98-105.

8. Kurt M., Gül M.S., Gül R., Aydın A.C., Kotan T. (2016). The effect of pumice powder self- compactability of pumice aggregate lightweight concrete. Construction and Building Materials 103, 36-46.

9. Muller A. C. A., Scrivener K.L., Skibsted J., Gajewicz A.M., McDonald P.J. (2015). Influence of silica fume on the microstructure of cement pastes: New insights from H NMR relaxometry. Cement and Concrete Research 74, 116-125.

10. Aydin A.C. (2007). Self compactability of high volume hybrid fiber reinforced concrete. Construction and Building Materials 21, 1149-1154.

11. Kurt M, Kotan, T., Gül, M.S., Gül, R., Aydin, A.C. (2016) The Effect of Blast Furnace Slag to Self-Compactability of Pumice Aggregate Lightweight Concrete, SADHANA Academy Proceedings in Engineering Sciences, 41(2), 253-264.

12. Aydın, A.C., Karakoç, M.B., Düzgün, O.A., and Bayraktutan, M.S. (2010). Effect of low quality aggregates on the mechanical properties of lightweight concrete, Scientific Research and Essays, 5 (10), 1133-1140.

13. Çalışkan S. (2003). Aggregate/mortar interface: influence of silica fume at the micro and macro- level. Cement and Concrete Composites 25, 557-564.

14. Erdoğan, T. Y. (2003). Beton. ODTÜ Geliştirme Yayıncılık ve İletişim, 741 p, Ankara.

15. Seslija M., Resic A., Radovic N., Vasic M., Dogo M., Jotic M. (2016). Laboratory Testing of Fly Ash. Tehnicki Vjesnik 23 (6), 1839-1848.

16. Nath, P., Sarker P. (2011). Effect of Fly Ash on the Durability Properties of High Strength Concrete. Procedia Engineering 14, 1149-1156.

17. Arioz E., Arioz Ö., Koçkar Ö.M. (2013). Mechanical and Microstructural Properties of Fly Ash Based Geopolymers. International Journal of Chemical Engineering and Applications, 4 (6), 397-400.

18. Nadaf M.B., Manda J.N. (2013.) Experimental Studies and Analyses for Basic Characterization of Fly Ash. Proceedings of 4th Global Engineering, Science and Technology Conference.
19. Wong Y.L., Lam L., Poon C.S., Zhou F.P. (1999). Properties of fly ash-modified cement mortar- aggregate interfaces. Cement and Concrete Research 29, 1905-1913.

20. Rong Z.D., Sun W., Xiao H.J., Wang W. (2014). Effect of silica fume and fly ash on hydration and microstructure evolution of cement based composites at low water-binder ratios. Construction and Building Materials 51, 446-450.

21. Tangüler M., Gürsel P., Meral Ç. (2015). Türkiye'de Uçucu Küllü Betonlar İçin Yaşam Döngüsü Analizi. ResearchGate.

22. Kruse K., Jasso A., Folliard K., Ferron R., Juenger M., Drimalas T. (2012). Characterizing Fly Ash. The University of Texas, CTR Technical Report, 6648 (1).

23. Kurt M., Aydın A.C., Gül M.S., Gül R., Kotan T. (2015). The effect of fly ash to self- compactability of pumice aggregate lightweight concrete. Indian Academy of Sciences Sadhana 40 (4), 1343-1359.

24. Vidivelli B., Mageswari M. (2010). Study on flyash concrete using SEM analysis. Journal of Environmental Research And Development 5 (1), $46-52$.

25. Liu J., Qiu Q., Xing F., Pan D. (2014). Permeation Properties and Pore Structure of Surface Layer of Fly Ash Concrete. Materials, 7, 4282-4296.

26. Ikram M. (2016). High volume fly ash-strength development in concrete: a review. International Journal of Advanced Structures and Geotechnical Engineering, 5 (2), 52-57.

27. Zheng C., Liua Z., Xub J., Lia X., Yaoa Y. (2007). Compressive strength and microstructure of activated carbon fly-ash cement composites. Chemical Engineering Transactions, 59, 475-480.

28. Stutzman PE. (2001). Scanning electron microscopy in concrete petrography. The American Ceramic and Society 59-72.

29. Temiz H., Karakeçi A.Y. (2002). An investigation on microstructure of cement paste containing fly ash and silica füme. Cement and Concrete Research 32, 1131-1132.

30. Sahoo S. (2016). A Review of Activation Methods in Fly Ash and the Comparison in Context of Concrete Strength. Journal of Basic and Applied Engineering Research, 3 (10), 883-887.

31. Elena J, Lucia MD. (2012). Application of x-ray diffraction (XRD) and scanning electron microscopy (SEM) methods to the portland cement hydration process. Journal of Applied Engineering Sciences 2 (15), 35-42.

32. Dorum A., Koçak Y., Yılmaz B., Uçar A. (2010). Uçucu Kül Katkılı Çimento Hidratasyonuna Elektrokinetik Özelliklerin Etkisi. Gazi Üniversitesi Mühendislik Mimarlık Fakültesi Dergisi, 25 (3), 449-457.

33. Uzbaș B., Aydın A.C., (2018). XRD Analysis of Mechanical Properties of Containig Fly Ash and Silica Fume Concrete. Sinop University Journal of Naturel Science, 3(2), 1-22. 